\title{
ИРРАЦИОНАЛЬНЫЙ МОДУС ПОЗНАНИЯ В УЧЕНИИ БЕРНАРДА КЛЕРВОСКОГО
}

\begin{abstract}
А.В. Тимофеев
«Новая философская энциклопедия» определяет соотношение рационального и иррационального в христианской мысли западного средневековья как «противопоставление разума и веры» [7]. В исторической перспективе такое противопоставление - явление относительно недавнее и восходит к трудам французских энциклопедистов эпохи Просвещения. Мыслители западноевропейского Средневековья, как и философы Нового времени, выводили свои тезисы из книг Священного Писания, утверждая органическую связь веры и разума. Этот принцип находит свое отражение и в учении французского теолога XII века, основоположника западной средневековой мистики святого Бернарда Клервоского.

Начиная с XII века, в западноевропейском религиозно-интеллектуальном пространстве доминируют два основных направления - схоластическое и мистическое. Для лучшего понимания гносеологической позиции св. Бернарда покажем различия между этими направлениями на примере латинского изречения «credo, ut intelligam» («верую, чтобы понимать»), определяющего принцип, согласно которому ударение на первой либо второй части тезиса обусловливает первичность разума или веры. Представим эволюцию этого тезиса в кратком историко-философском дискурсе, обращаясь к вопросам апофатического и катафатического богословского подходов, метафизической и экзистенциальной проблематики в эпистемологическом пространстве западной средневековой мысли.

Августин Блаженный первым в христианской философии поставил веру и разум во взаимозависимость. Открыв, таким образом, новую
\end{abstract}


эпоху в истории Западной мысли, гиппонский епископ четко определил порядок их отношений:

Итак, вера предшествует разумению, но ее иначе и не понять. И не дай Бог, если она не предшествует разуму, тогда ведь она иррациональна! Следовательно, вполне естественно, если вера предшествует разумению в том, что мы не можем пока понять; но несомненно и то, что разум споспешествует вере, убеждая идти вперед! (цит. по: [10, c. 30]).

Основная идея теории познания бл. Августина, жившего в эпоху установления христианских догматов - понимание есть награда веры: «Человек должен быть разумным, чтобы хотеть искать Бога» («О Троице»). По мысли Августина, Бог наделяет души знаниями путем освещения (лат. illuminations), эту теорию позже назовут иллюминизмом. Освещение - сверхъестественный факт проявления божественной любви. Озаряющий свет исходит от «Отца светов» через Слово, но природа этого света (тварная или же нетварная) здесь не раскрывается; ясно лишь, что этот свет - благодатный, рациональным путем не постигаемый, т. е. сверхразумный.

Западная христианская мысль, как правило, ассоциируется с катафатическим методом богословия, однако говорить о гносеологии Августина как о «теоретическом обосновании отказа от апофатизма» (Х. Яннарас), по нашему мнению, будет преувеличением. Скорее, нужно согласиться со словенским философом Г. Коциянчичем, по мысли которого теория познания Августина представляет собой «катафатически выраженный апофатизм» [11, с. 153] - христианское переосмысление платонического (неоплатонического) апофатизма. Действительно, в своих сочинениях бл. Августин никогда не говорил о рассудочной мысли, которая могла бы приблизиться к абсолютному Бытию; в него проникает лишь «духовный ум»(intellectus mentis), или внутренний взгляд (interior aspectus), который гиппонский епископ, соответственно патристической практике, отождествляет с библейским «знанием сердца». Определяя веру как личную встречу и онтологическую причастность, Августин утверждал, что только то видение, которому должен быть причастен тот, кто хочет рефлексировать его, прикасается тайны «ipsum esse», или «того, что истинно есть» $[11$, c. 152]. После безуспешных усилий достичь истины и, по сути, веры с помощью одного лишь разума, Августин обнаружил, что «рациональную истину о Боге, о которой говорили философы, можно постичь сразу и безо всяких ошибок, простым актом веры» [6]. Таким образом, бл. Августин, опираясь на собственный духовный опыт, установил, что 
самый верный путь постижения истины начинается с веры и ведет от Откровения к разуму. Начиная с четвертого века и до наших дней, всегда существовали мыслители, которые поддерживали августиновский принцип христианской Мудрости.

Так, в XI веке «отец схоластики» Ансельм Кентерберийский открыто стоял на позициях христианина, который, веруя, размышляет о разумном обосновании своей веры. Как он сам неоднократно заявлял, его намерением было пересказать то, что уже было высказано его учителем Августином. Другими словами, его аргументы были выражением более общей установки - «веры, ищущей уразумения» («fides quaerens intellectum»). Следует отметить, что именно Ансельму, а не Августину принадлежит тезис «credo, ut intelligam» (верить, чтобы понимать). Ансельм пишет:

Я не стремлюсь, о Господи, проникнуть в величие Твое, ибо никоим образом я не полагаю, что мое понимание способно на такое, но я стремлюсь понять хоть в какой-то степени Твою истину, в которую мое сердце верит и которую оно любит. Ибо я не ищу того, чтобы понять, дабы уверовать, а я верю, дабы понять. Ибо я верю также в то, что если бы я не уверовал, то я бы и не понял (цит. по: [6]).

Последователь Ансельма в схоластическом методе обоснования веры, Петр Абеляр в XII веке рационализирует отношения веры и разума, полагая обязательным условием веры понимание, и, таким образом, утверждает новый принцип, противоположный принципу Ансельма - «intelligo, ut credam» («понимаю, чтобы верить»). Если вера, полагает Абеляр, как откровение абсолютного Разума (Логоса) всегда разумна, то разум стоит несколько выше веры. Поэтому вера должна иметь рассудочное основание, что и определяет, по мнению Абеляра, первичность знания перед слепой верой:

Мы же тем скорее сделаемся учениками Христа, Который есть истина, чем сильнее мы будем подкреплены истиною оснований. Ведь Сам Сын называется Logos'oм, мудростью Бога, поэтому Ему особенно свойственна та наука, которая, подходит к нему и по своему названию, потому что, как мы называемся христианами по Христу, так и логика, по-видимому, именуется в особенности по Логосу (цит. по: [4, c. 161]).

В учении Петра Абеляра явственно прослеживается радикальное изменение учения о постижении истины, «которая отождествляется с ее определением, а познание (то есть обладание истиной) - с индивидуальным усвоением формулировок» [13]. В своем трактате «Введение 
в теологию» («Introductio ad theologiam») Абеляр называет Бога сущностью (essentia), даже существом: «как таковой, он является одним существом среди прочего, хотя наиболее совершенным и создателем всех остальных» (цит. по: [14, с. 83]). Обращаясь к древнегреческой онтологии, предполагающей первенство понятия сущности, сущностную и логическую заданность бытия, Абеляр отказывается от апофатизма теологических определений, тем самым отдаляясь от «примата жизни и ее ипостасного проявления в личности, взятой в своей экзистенциальной инаковости и свободе» [13].

И хотя и Ансельм, и Абеляр все еще повторяют формулу Августина «понимаю, чтобы верить, и верую, чтобы понимать», тенденция к ее внутреннему разрыву, открывающая возможность философствования вне веры, становится все очевиднее. Христианские мыслители XIII-XIV веков, двигаясь в этом направлении, выскажут предположения, что вера и разум ведут либо различными путями к одной Истине (Фома Аквинский), либо свидетельствуют о существовании двух не связанных друг с другом истин (Уильям Оккам). Таким образом, схоластика в своем развитии пытается исчерпать процесс познания возможностями индивидуального разума. Эта тенденция выступает определяющим фактором, обусловившим гносеологический поворот от онтологии как метафизики бытия к учениям о бытии познаваемых объектов.

Для Бернарда Клервоского, основоположника западной средневековой мистики и ярчайшего представителя «монашеской теологии» (Ж. Леклерк), вопрос о первичности веры и знания бесспорно решается в пользу веры, при этом само знание не отрицается, как не отрицается и философия. Следует подчеркнуть, что «последний из Отцов» понимает философию в святоотеческой трактовке «христианской мудрости», кардинально отличающейся от «игры в диалектическое искусство» [17] схоластических диспутов. «Вопреки распространенному мнению Бернард вовсе не нападает на философию, - пишет Р. Браг, - но зато беспощадно атакует самих философов» [2, с. 99]. Для св. Бернарда термин philosophia имеет положительную окраску - как определение интеллектуальных исследований христианами своей веры.

Отношение Бернарда к «светским философам», напротив, глубоко негативное. Это хорошо иллюстрирует цитата из трактата «О размышлении» :

Они называют себя любознательными (философами), мы же правильнее назовем их любопытными и суетными. Среди них, есть такие, ко- 
торые хотят знать, чтобы продавать свое знание за деньги и почести, а это - недостойное стяжание (цит. по: [5, с. 67]).

Постулируя любопытство (curiositas) в сочинении «О ступенях смирения и гордыни» как начало духовного регресса, первый шаг нисхождения в грех, Бернард порицает тех, кто стремится к знанию ради знания, тем более, ради материальной выгоды. При этом рациональное знание для Клервоского не является чем-то дурным, опасно именно досужее любопытство, которое отвлекает человека от его истинной цели - познания Бога.

Всякое знание хорошо, если основано на истине. Но время, данное человеку, кратко, и потому он больше должен заботиться о том знании, которое ближе к спасению. Есть такие, которые хотят знать, чтобы назидать других,- это любовь, и такие, которые хотят знать для собственного назидания, а это - мудрость. Только последние два разряда людей не злоупотребляют знанием (цит. по: [5, с. 67-68]).

Таким образом, стремление к знанию ради «собственного назидания», которое св. Бернард Клервоский называет мудростью, неразрывно связано со стремлением человека к Богу; такое знание - наивысшее для христианина. Другая, столь же высокая цель, для исполнения которой необходимо знание, - «назидание ближнего», т. е. проповедь. Для аббата из Клерво главной чертой истинной христианской философии выступает ее практичность. «Петр и Павел, - пишет Бернард, научили меня жить. Как вы думаете, это мелочь, чтобы знать, как жить?» (цит. по: [15, с. 50]). Возвращаясь к древнему пониманию философии как «духовного упражнения», св. Бернард определяет суть философии в том, что она требует этико-аскетического труда, что она должна быть «философией, которой живут»; упражнения эти должны быть «духовными», поскольку «содержат целостный дух, целостный образ жизни» [11, с. 74$]$.

Говоря о позитивном контексте употребления настоятелем Клерво термина «философия», следует отметить, что Бернарду удается вписать слово philosophia даже там, где текст является священным, что освобождает его от использования другого, библейского слова sapientia (мудрость). В проповеди 43 на Песнь Песней Бернард заменяет sapientia в 1 Kop. 2.2 на philosophia, определяя тем самым собственный взгляд на познание: «Знать Иисуса, и притом распятого,- вот моя тонкая, внутренняя философия» [18]. Следуя традиции Августина, св. Бернард полагает, что вера должна предшествовать знанию. Однако подход к обоснованию истин веры у Б. Клервоского отличается как от принципа Августина, так и от принципа Абеляра. 
Связь веры и знания, понимаемого аббатом как опыт духовного постижения, определяет латинский тезис, которому следует св. Бернард: «credo, ut experiar» («верую, чтобы испытать»), где глагол «испытывать» подразумевает «духовное постижение», «духовный опыт». В трудах Бернарда можно найти 473 примера использования в той или иной форме глагола «испытать» (experiri). K ним надо добавить спектр близких синонимов, ибо настоятель также говорит об обучении на опыте (comperire), чувстве (sentire), дегустации (gustare), переживании (pati), демонстрации (probare) и желании опыта (desiderare). Почти всегда смысл этих терминов является положительным [16, с. 14].

«Сегодня читаем мы в книге опыта»,- пишет Бернард в третьей проповеди на Песнь Песней, в аллегориях «трех лобзаний - стоп, длани и уст Христа» толкуя три восходящих этапа совершенствования души - покаяние в грехах, укрепление во благе, единение с Богом.

Сначала к стопам припадем и горько оплакиваем перед очами Господа нас сотворившего, нами сотворенное. Затем взыскуем руки возвышающего и укрепляющего колена расслабленные. И, наконец, когда того многими мольбами и слезами достигнем, тогда только, пожалуй, дерзаем поднять голову к самым устам славы, дабы, в трепете и робости не только воссозерцать, но и облобызать, ибо Господь Христос есть дух перед лицом нашим, к коему и припадаем в священном лобзании, «дух един» по снисхождению его становимся [8, с. 434-435].

В последней фразе, основываясь на словах ап. Павла «соединяющийся с Господом есть один дух с Господом» (1 Kop. 6:17), св. Бернард говорит о душе, которая, обретая благодать через дар Божий, соединяется с Ним в единый дух, достигая предела Божественной любви. Для Клервоского эта любовь и есть настоящее знание, где самые значительные и глубокие истины приобретаются в непосредственном опыте мистического единения. Такое непосредственное созерцание Бога у св. Бернарда, как и у представителей восточной церковной мистики, имеет аналогию с ангельским способом познания всего сущего: «Если мы на высшей степени созерцаем Слово, - пишет Бернард, - то, подобно ангелам, видим все, что словом создано» (цит. по: [3, с. 124]).

Примечательно, что именно Бернард Клервоский первым в западной христианской традиции определяет различие между апофатическим и катафатическим созерцанием, описывая ту роль, которую «ангелы играют во внедрении в воображение образов, понятий языка, через которые чистый свет Божий может быть понят и передан другим» $[9$, с. 435]. Эти блаженные духи, по Бернарду, способны познавать причину всего существующего не верою или мнением, но путем непосред- 
ственного созерцания:

Небесные духи не нуждаются в том, чтобы из творения добывать познание творца [...] ангелы познают твари в том, в чем они лучше, чем в себе самих. Поэтому они не нуждаются в телесном чувстве, но сами для себя составляют чувство, ощущая себя самих (цит. по: [3, с. 130]).

Разделяя ангелов на девять ликов, аббат воспроизводит «небесную иерархию» ангельских сил, предложенную Дионисием Ареопагитом. По степени участия в Боге ангелы заимствуют от Него и воспроизводят в себе в различной степени те свойства, которые принадлежат Богу. Так ангелы в силу присущего им непосредственного созерцания и участия в Его блаженстве отражают божественные совершенства и служат в некоторой степени выражениями свойств Божиих, «участвуя в промыслительной деятельности Бога о мире и человеке, как его слуги в исполнении Его воли для поддержания добра» [3, с. 131].

В данном контексте представляется верным замечание Г. Коциянчича: «для латинских отцов на первый взгляд характерна катафатическая "онтотеология" [...] Но смысл "бытия" понимается у этих отцов подчеркнуто апофатически» [11, с. 150]. Действительно, говоря о личностном Боге своего опыта, св. Бернард использует «мистическую инверсию апофатизма» (Г. Коциянчич):

Ничего не может быть без Него, как и Он не может быть без Себя. Он сам себе все. И поэтому лишь Он (solus est ipse) тот, который является бытием (esse) для себя и бытием всех (цит. по: [11, с. 150]).

В отличие от Абеляра святой Бернард называет Бога не существом или сущностью (essentia), а скорее бытием, существованием (esse). Для Абеляра высшее существо - существительное, тогда как для св. Бернарда это глагол: «Как таковой Он не является одним среди других, Он сам акт существования всех вещей» (qui suum ipsius est et omnium esse) (цит. по: [14, с. 83]). В своем понимании Бога как Абсолютного Бытия средневековый мистик близок идеям православия, что подтверждает цитата из книги ведущего православного философа современности Х. Яннараса:

Имя Божие не существительное, называющее Бога в ряду других сущностей того же порядка, и не прилагательное, сообщающее Ему некое характерное качество. Это - глагол; это - звучащее в устах человеческих эхо того Глагола [...], посредством которого Бог указывает на Себя Самого как на Сущего, единственного истинно-Сущего [13]. 
Теоцентрический монизм Б. Клервоского делает все зависимым от Бога, однако аббат избегает пантеизма, объясняя, что субстанция Бога и вещей суть различны - Бог является их причиной, но не материалом. Принимая «божественную форму», душа человека в эсхатологической полноте будущей жизни (прообразом которой могут служить переживания религиозно-мистического экстаза), становится «причастной Божеского естества» (2 Пет. 1,4$)$, т. е. со-причастной Божественному образу бытия. Таким образом, отношения между Богом и человеком мыслятся святым Бернардом апофатически, однако путь отрицания не растворяется в некой пустоте, поглощающей и субъект и объект, а приводит к мистическому опыту личностного присутствия сокрытого Бога. Человеческая личность не растворяется, «но достигает предстояния лицом к лицу с Богом, соединения с Ним по благодати без смешения» $[12$, с. 390]. Пропасть между тварным и нетварным может быть преодолена на уровне модуса существования, «общего обеим природам, суть которого в личностном бытии» [13].

Таким образом, гносеологическая позиция св. Бернарда Клервоского основывается на глубоко личностном иррациональном переживании Бога, которое дает непосредственное познание высшей Истины в виде религиозного акта. Рациональные доказательства веры не игнорируются, но им отводится второстепенное место в качестве процесса познания. Не разум и телесные восприятия, но духовные чувства позволяют познать мир, Бога, самого себя. Эти духовные чувства (которые сродни харизме, даруемой высшими мистическими силами) с особой отчетливостью отражают божественный образ человека, восстановление которого зависит как от усилий самого верующего, так и от иррациональной помощи божественной благодати. Личностно-экзистенциальный характер мистики Б. Клервоского открывает путь широкому развитию антропологической проблематики в средневековой философии. Искреннее чувство строгой религиозности, направленное в сторону деятельного христианского благочестия предвосхищает появление субъективно-индивидуалистического вектора идей протестантизма. Основатели Реформации Кальвин и Лютер высоко ценили учение Б. Клервоского. При всей своей неприязни к католическому духовенству, Лютер говорил о Бернарде: Если существовал когда-либо богобоязненный и набожный монах, то это был св. Бернард, которого одного я ставлю выше всех монахов и попов целого мира» (цит. по: [1]). Экзистенциальный и нравственно-практический характер сочинений святого Бернарда позволяет его учению оставаться актуальным на протяжении уже около 900 лет. 


\section{Литература}

[1] Бернард Клервоский. Энциклопедический Словарь Ф.А.Брокгауза и И.А.Ефрона [Электронный ресурс]. - Режим доступа: http://www.vehi.net/brokgauz/all/011/11260.shtml

[2] Браг Р. Антропология смирения // Вопросы философии. 1999. - № 5. - С. 99-113.

[3] Вертеловский А.Ф. Западная средневековая мистика и отношение ее к католичеству. - Харьков : Типография Окружного Штаба, 1888. - Вып. 1.

[4] Гаусрат A. Средневековые реформаторы: Пьер Абеляр. Арнольд Брешианский. - М. : Книжный дом «Либроком», 2012.

[5] Геръе В. Западное монашество и папство. - М.: Т-во «Печатня С.П. Яковлева», 1913.

[6] Жильсон Э. Разум и откровение в Средние века [Электронный ресурс].-Режим доступа: http://filosof.historic.$\mathrm{ru} /$ books/item/f00/s00/z0000745/st000.shtml

[7] Катасонов В.Н. Иррациональное. Новая философская энциклопедия [Электронный ресурс].-Режим доступа: http://iph.ras.ru/elib/1289.html

[8] Клервоский Б.. Проповеди на Песнь Песней // Антология средневековой мысли (Теология и философия европейского Средневековья): в 2 т. / Под ред. С.С. Неретиной. - СПб. : РХГИ, 2001. T. 1. - С. 432-444.

[9] Клестов A.А. Бернард Клервоский // Антология средневековой мысли (Теология и философия европейского Средневековья): в 2 т. Т. 1 / Под ред. С.С.Неретиной. - СПб. : РХГИ, 2001. - Т. 1. C. $427-430$.

[10] Клестов A.A. Интеллектуальный ренессанс XII в. и раннее францисканство XIII в., их значение для современной Европы // Вестник Русской христианской гуманитарной академии. - 2007. - № 1. - C. 27-42.

[11] Кочиянчич Г. Введение в христианскую философию.-СПб.: Алетея, 2009. 
58 Иррациональный модус познания в учении Бернарда Клервоского

[12] Лосский В.Н. Очерк мистического богословия Восточной Церкви. Догматическое богословие. - СТСЛ, 2012.

[13] Яннарас X. Вера Церкви. Введение в православное богословие [Электронный ресурс].-Режим доступа: http:// azbyka.ru/hristianstvo/sut/vera_tcerkvi_13-all.shtml\#a13_5

[14] Burch G. Early medieval philosophy. - New York: King's Crown Press, 1951.

[15] Evans G.R. Bernard of Clairvaux. - New York-Oxford: Oxford University Press, 2000.

[16] McDonnell K. Spirit and experience in Bernard of Clairvaux // Theological Studies. - 1997. - № 58. - P. 1-18.

[17] S. Bernardi Claraevalensis. Epistola CXC. Ad Innocentium Pontificem, de erroribus quibusdam Petri Abaelardi. Opera omnia [Электронный pecypc]. - Режим доступа: http://www.binetti.ru/bernardus/05_2.shtml

[18] S. Bernardi Claraevalensis. Sermo in Cantica canticorum XLIII, 4. Opera omnia [Электронный pecypc]. - Режим доступа: http://www.binetti.ru/bernardus/86_3.shtml

Надійшла до редакчіï 22 лютого 2015 р. 